\title{
Calculation of Building Foundation Settlement Caused by Shield Tunnel Construction
}

\author{
Chun-lai Chen ${ }^{1}$, Hao-qiang $\mathrm{Yu}^{1}$, Gang Wei ${ }^{1, *}$, Xiao Wang ${ }^{2}$, and Qi Ye ${ }^{3}$ \\ ${ }^{1}$ Department of Civil Engineering, Zhejiang University City College, 310015, Hangzhou, China \\ ${ }^{2}$ College of Civil Engineering and Architecture, Zhejiang University, 310058, Hangzhou, China \\ ${ }^{3}$ Pypun Engineering Consultants Ltd., Hong Kong
}

Received 1 March 2015; Accepted 29 April 2015

\begin{abstract}
The formation of settlement troughs for the case when there are buildings above a tunnel is different from the case without buildings present on the ground surface during construction of shield tunnels below the ground. By considering the influence of building stiffness, previous studies have calculated the surface of building subsidence during shield construction, but it was assumed that the soil around the tunnel would shrink evenly toward the center and that the focus should be fixed and the foundation stiffness of the building was not considered. The method used in this paper modifies the forward method, by considering a uniform ground movement model for shield tunnels and the foundation stiffness and depth. The calculated values are compared to the measured values, the values of the other method and also values obtained using finite-element simulation. The effects of the equivalent elastic modulus of buildings $E_{1}$, the depth of the tunnel axis from the ground $h$ and the distance between the tunnel axis $L$ to the settlement of foundations are also analyzed. The results show that the values obtained by the present calculation method are more similar to the measured and finite-element simulation values than the values obtained using the other method. The settlement of foundations is found to decrease with increasing $E_{1}, h$ and $L$.
\end{abstract}

Keywords: shield tunnel, building, foundation settlement, ground loss

\section{Introduction}

Urban ground traffic congestion is becoming increasingly serious in China. Tunnels are therefore widely used in order to ease congestion[1], [2], [3]. The construction of shield tunnels will inevitably remold the soil mass and cause settlement of building foundations. This may lead to a series of problems such as building tilting, cracking or even collapsing, etc., which will affect the normal functioning and the safety of buildings [4], [5]. The ground settlement occurring during shield tunnel construction is mainly due to soil loss. The formation of the settlement for the case when there are buildings above the tunnel is different from the case without buildings present.

Currently, the main research methods that have investigated the effects of underground tunnel construction on adjacent buildings include the analytical method [6], [7], [8], the finite-element method [9], [10], [11], [12] and the practical measurement method [13], [14], [15]. Among these, the finite-element method and the practical measurement method have been most frequently applied, and the analytical method less frequently applied. Wenbiao Ouyang et al. [6] derived a calculation formula for building ground surface settlement caused by shield construction by applying the solution of Verruijt and Booker [16]. The effects of the building stiffness were considered, and the

* E-mail address: weig@zucc.edu.cn ISSN: 1791-2377 @ 2015 Kavala Institute of Technology. All rights reserved. equivalent stiffness principle was applied to make the building equivalent to the soil stratum that had the same properties as the underlying soil layer. However, the solution of Wenbiao Ouyang assumed that the ground around the tunnel had uniform radial shrinkage, so that the solved maximum settlement value was relatively small and the scope of the settlement trough was relatively large. Moreover, the stiffness of the building foundation was not considered. Therefore, some disadvantages exist in this method and hence it is subject to further study here.

This paper, by applying solutions of the uniform ground movement model for shield tunnels [17], and by considering the stiffness of the building foundation and the non-radial contraction of the tunnel soil, through amendment to the Wenbiao Ouyang solution, derives the value of the settlement at the bottom of the building foundation caused by shield construction of single-track and double-track tunnels. In addition, two cases are analyzed for comparison with the measured values, the calculated values using the Wenbiao Ouyang solution and the finite-element simulation values. This paper also studies the influences of the building's equivalent elastic modulus, the tunnel axis depth and the axis distance of the double-track tunnel on foundation settlement.

\section{Calculation of Building Foundation Settlement Caused by Shield Tunnel Construction}




\subsection{Disadvantages of Existing Methods}

Wenbiao Ouyang et al. [6] proposed that when the length of a building covers the whole influence scope of the settlement trough and the tunnel passes directly under the building, the building can be converted into a homogeneous stratum (see Fig. 1 for the conversion sketch). Fig. 1(a) shows the original coordinate system, with the coordinates expressed as $x$ and $z$, and Fig. 1(b) shows the converted coordinate system, with the coordinates expressed as $x^{\prime}$ and $z^{\prime}$. In the figure, $x$ is the transverse horizontal distance from the tunnel axis, $x=x^{\prime}, z$ is the vertical distance from the calculated point to the original ground surface, $z^{\prime}$ is the vertical distance from the calculated point to the converted ground surface, $H$ is the tunnel axis depth after equivalence, $h$ is the tunnel axis depth, $h^{\prime}$ is the building height and $R$ is the tunnel excavation radius.

(a)

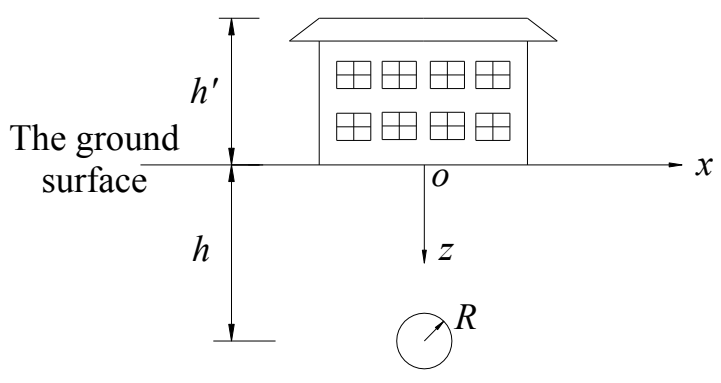

(b)

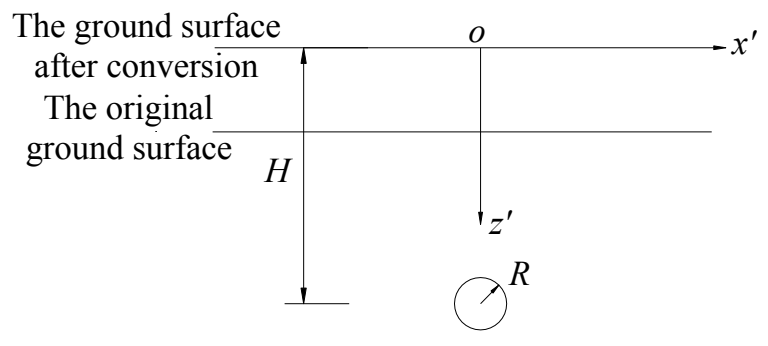

Fig.1. Diagram of a single tunnel under a building, and conversion of the soil

The coordinate conversion formula is:

$$
H=h+h^{\prime} \sqrt[3]{E_{1} / E_{2}}
$$

$z^{\prime}=h^{\prime} \sqrt[3]{E_{1} / E_{2}}+z$

where $E_{1}$ is the equivalent elastic modulus of the building and $E_{2}$ is the soil elastic modulus. Refer to Wenbiao Ouyang et al. [6] for the specific conversion process.

As shown in Fig. 1(b), the vertical coordinate at the original ground surface $z^{\prime}=H-h$, i.e. $h^{\prime} \sqrt[3]{E_{1} / E_{2}}$, and there is no change to the horizontal coordinate (i.e. $x=x^{\prime}$ ) The converted coordinate is applied to the Verruijt and Booker solution, with the calculation formula for the settlement caused by the single-track tunnel construction obtained as:

Where $\varepsilon$ is the axial diameter shrinkage parameter of the tunnel, $\delta$ is the vertical displacement parameter of the tunnel, $z_{1}=z^{\prime}-H, z_{2}=z^{\prime}+H, r_{1}=x^{\prime 2}+z_{1}^{2}, r_{2}=x^{\prime 2}+z_{2}^{2}, m=1 /(1-2 \mu), k=\mu(1-$ $2 \mu$ )and $\mu$ is the Poisson's ratio of the substratum material.

$$
\begin{aligned}
& U=-\varepsilon R^{2}\left(\frac{z_{1}}{r_{1}{ }^{2}}+\frac{z_{2}}{r_{2}{ }^{2}}\right)+\delta R^{2}\left[\frac{z_{1}\left(k x^{2}-z_{1}{ }^{2}\right)}{r_{1}{ }^{4}}+\frac{z_{2}\left(k x^{2}-z_{2}{ }^{2}\right)}{r_{2}{ }^{4}}\right] \\
& +\frac{2 \varepsilon R^{2}}{m}\left[\frac{(m+1) z_{2}}{r_{2}{ }^{2}}-\frac{m z\left(x^{2}-z_{2}{ }^{2}\right)}{r_{2}{ }^{2}}\right] \\
& +\frac{2 \varepsilon R^{2}}{m}\left[\frac{(m+1) z_{2}}{r_{2}{ }^{2}}-\frac{m z\left(x^{2}-z_{2}{ }^{2}\right)}{r_{2}{ }^{2}}\right] \\
& -2 \delta R^{2} H\left[\frac{x^{\prime 2}-z_{2}{ }^{2}}{r_{2}{ }^{2}}+\frac{m}{m+1} \frac{2 z z_{2}\left(3 x^{\prime 2}-z_{2}{ }^{2}\right)}{r_{2}{ }^{6}}\right]
\end{aligned}
$$

The vertical coordinate at the original ground surface $z^{\prime}=H-h$ is substituted into formula (3), so that the settlement at the building's ground surface caused by the single-track tunnel construction can be solved.
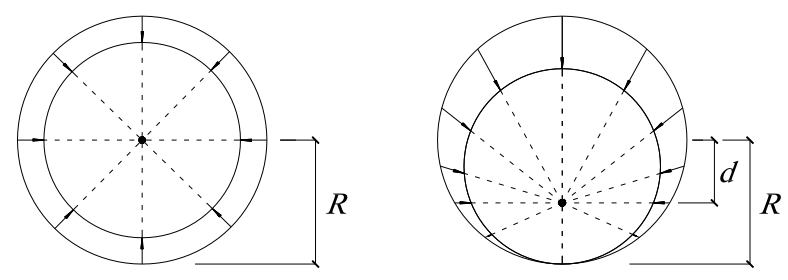

Fig.2. Models of soil movement

The Verruijt and Booker solution [16] assumes that the ground around the tunnel shrinks uniformly toward the tunnel center. However, according to the research of Gang Wei [18], a ground loss model with tangential double circles should be applied. The movement focus of the ground around the tunnel alters between the center point and the bottom of the tunnel. Fig. 2(a) shows the Verruijt and Booker solution model (uniform radial movement of the ground around the tunnel), and Fig. 2(b) shows the uniform ground movement model of a shield tunnel [18]. In the figure, $d$ is the distance from the ground movement focus to the tunnel center point. Therefore, the maximum ground surface settlement value solved by the Wenbiao Ouyang solution is relatively small and the scope of the settlement trough is relatively large, which can be seen from the comparison chart of the calculated value and the measured value in Wenbiao Ouyang et al. [6].

During the computation process, the Wenbiao Ouyang solution only converts the building structures above the ground into the soil stratum, with building foundations not being considered, and the settlement of the original ground surface location is set to be equal to the settlement of the building. In reality, the building foundations in a project have a certain stiffness, so it is more reasonable that the settlement at the original base plane is calculated and set to be equal to the settlement of the building.

\subsection{Method Proposed in this Study}

This paper, in view of the disadvantages of the Wenbiao Ouyang solution, applies solutions from the more reasonable uniform ground movement model for the shield tunnels. In addition, the building foundation stiffness is considered. The building settlement is defined through calculation of the settlement at the original base plane, which is more consistent with the actual working conditions.

Through the application of the solutions from the uniform ground movement model for shield tunnels, the paper obtains a two-dimensional solution for the ground settlement caused by the ground loss during construction of 
Chun-lai Chen, Hao-qiang Yu, Gang Wei, Xiao Wang, and Qi Ye

Journal of Engineering Science and Technology Review 8 (3) (2015) 179 - 184

a single-track shield tunnel (see Wei [17] for details). With reference to the Wenbiao Ouyang solution, a coordinate conversion system can be obtained (see Fig. 3). Fig. 3(a) shows the original coordinate system with the foundation being considered, and Fig. 3(b) shows the converted coordinate system with the foundation being considered. In the figure, e is the buried depth of the building foundation and $H^{\prime}$ is the tunnel axis depth after equivalence with the foundation being considered, $H^{\prime}=(h-e)+\left(h^{\prime}+e\right) \sqrt[3]{E_{1} / E_{2}}$.

(a)

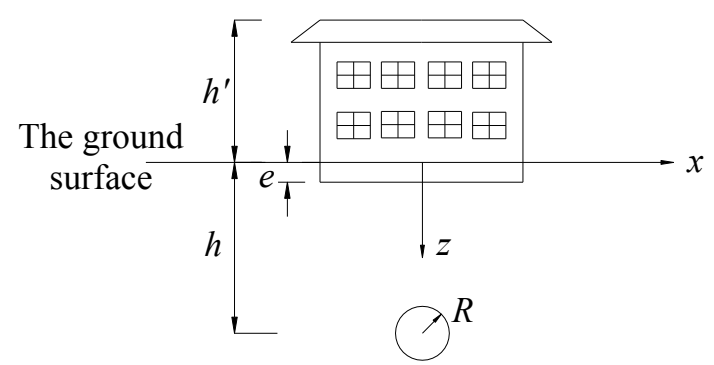

(b)

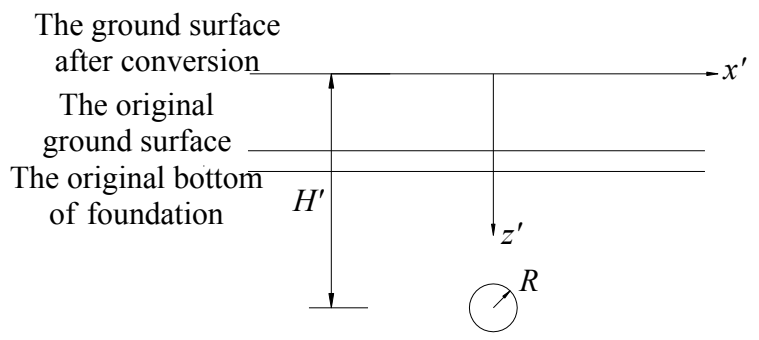

Fig.3. Diagram of single tunnel under a building, and conversion of the soil considering the foundation

As shown in Fig. 3(b), there is no change to the horizontal coordinate (i.e. $x=x^{\prime}$ ). The converted coordinate is applied to the solutions from the uniform ground movement model for shield tunnels. The ground settlement formula when the single-track shield tunnel passes directly below the building can be established as follows:

$U_{z}=\frac{R^{2}}{2} \cdot\left\{\begin{array}{l}\frac{H^{\prime}-z^{\prime}}{x^{2}+\left(H^{\prime}-z^{\prime}\right)^{2}}+\frac{H^{\prime}+z^{\prime}}{x 2+\left(H^{\prime}+z^{\prime}\right) 2} \\ 2 z^{\prime}\left[x^{2}-\left(H^{\prime}+z^{\prime}\right)^{2}\right] \\ {\left[x^{2}+\left(H^{\prime}+z^{\prime}\right)^{2}\right]^{2}}\end{array}\right\}$.
$\frac{4 R g-g^{2}}{4 R^{2}} B \exp \left[\frac{x^{\prime 2} \ln \lambda}{\left(H^{\prime}+R\right)^{2}}+\frac{Z^{\prime 2}(\ln \lambda-\ln \omega)}{\left(H^{\prime}+d\right)^{2}}\right]$

where $g$ is the equivalent ground loss parameter. The calculation formulae for the three parameters $\lambda, \omega$ and $B$ are the following:

$$
\begin{aligned}
& \lambda=\frac{1}{4}-\frac{g}{\pi R \eta}\left[\arcsin \left(\frac{d}{R-g / 2}+\sqrt{1-\left(\frac{d}{R-g / 2}\right)^{2}}-1\right)\right] \\
& \omega=\frac{1}{2}-\frac{g}{\pi R^{2} \eta}(R-g / 4) \arcsin \left(\frac{d}{R-g / 4}\right)
\end{aligned}
$$

$$
B=\frac{4 h\left[h+d-\sqrt{(h+d)^{2}-\eta(R+d)^{2}}\right]}{R \eta(R+d)}
$$

where $\eta$ is the ground loss ratio. Refer to references [19], for selection of specific parameter values in the formulae.

A different settlement trough forms when a double-track shield tunnel passes under a building than for a single-track shield tunnel. When the tunnel spacing is sufficient, the settlement curve presents a W shape. The settlement calculation formula for a double-track shield tunnel passing under a building can be regarded as the superposition of the two single-track shield tunnel calculation formulae, with the only difference being the different reference horizontal coordinates (see Fig. 4). In the figure, $L$ is the axis horizontal spacing of the double-track tunnel. The ground settlement formula for the double-track shield tunnel passing directly below the building is:

$U_{\text {zdouble }}=U_{\text {zsingle }}\left(x+L / 2, z^{\prime}\right)+U_{\text {zsingle }}\left(x-L / 2, z^{\prime}\right)$

The vertical coordinate at the original foundation $z^{\prime}=H^{\prime}$ $h+e$ is substituted into formula (4) and formula (8), and the settlement at the building base plane during the construction of the single-track and double-track shield tunnels can be solved.

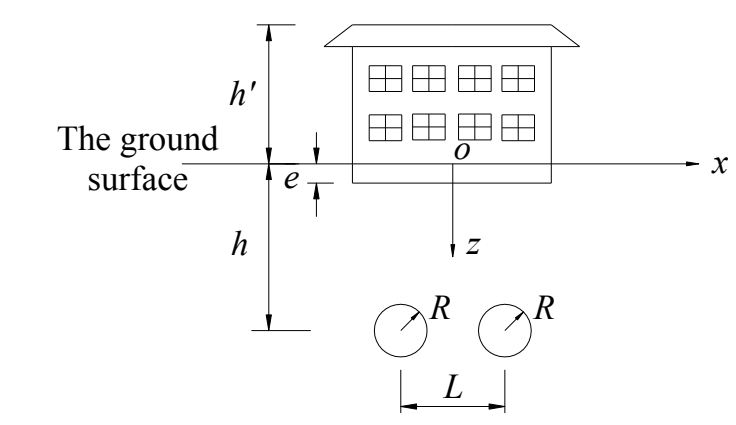

Fig.4. Twin tunnels passing under a building

\section{Case Analysis}

\subsection{Chongsi Building of Xuhui Middle School}

Shanghai Rail Transit Line 11 passes directly below the Chongsi Building of Xuhui Middle School. The tunnel diameter is $6.2 \mathrm{~m}$ and the tunnel axis depth is about $22.7 \mathrm{~m}$. The axis spacing between the two tunnels is about $16.5 \mathrm{~m}$. Chongsi Building has a length of around $66 \mathrm{~m}$ and a height of $23 \mathrm{~m}$, and consists of four floors. The equivalent elastic modulus for the Chongsi Building after conversion is $E_{1}=50$ $\mathrm{MPa}$. The ground is considered to be a homogenous linear elastic material. As per the empirical formula $E_{2}=2.5-3.5 E_{\mathrm{s}}$ ( $E_{\mathrm{s}}$ is the compression modulus of the ground) [20], for the project, $E_{\mathrm{s}}$ is chosen to be $3 \mathrm{MPa}$ and $E_{2}$ is chosen to be 8 $\mathrm{MPa}$. The Poisson ratio of the ground is chosen to be 0.3 and the excavation stress release factor is chosen to be 0.15 . The settlement measuring points were provided at the Chongsi Building during construction of the tunnel. See Fig. 5 for the lateral ground surface settlement values calculated by Wenbiao Ouyang [6] and the measured settlement values.

When the method proposed by this paper is applied to the calculation, the $1.5 \mathrm{~m}$ buried depth of the building foundation is considered. After conversion, the Chongsi Building is equivalent to a soil stratum $45.13 \mathrm{~m}$ thick, with the same properties as the soil stratum below it. The 
Chun-lai Chen, Hao-qiang Yu, Gang Wei, Xiao Wang, and Qi Ye

/Journal of Engineering Science and Technology Review 8 (3) (2015) 179 - 184

calculation parameters are chosen as follows: $g=38.87 \mathrm{~mm}$, i.e. $\eta=1.25 \%$, and $d=0.45 R$. See Fig. 5 for the lateral settlement curve of the foundation calculated by the method proposed here. As shown in the figure, compared with the method of Wenbiao Ouyang, the settlement curve derived by the current method presents "deep and narrow", with the calculation results being more consistent with the measured settlement curve of the building. This demonstrates the reliability of the proposed method. The reasons for the deviation between the values calculated by this method and the measured values are the following. During calculation, this method assumes that the double-track tunnel has a less mutual effect, and the calculation parameters for the doubletrack tunnel are chosen to be the same. Therefore, the settlement curve shows a symmetrical distribution. However, during actual construction, two tunnels cannot be constructed simultaneously, and the maximum total settlement often favors the first excavated tunnel side. So, when the method proposed here is applied to the calculation, the selection of parameters needs to be optimized in order to minimize differences with actual conditions.

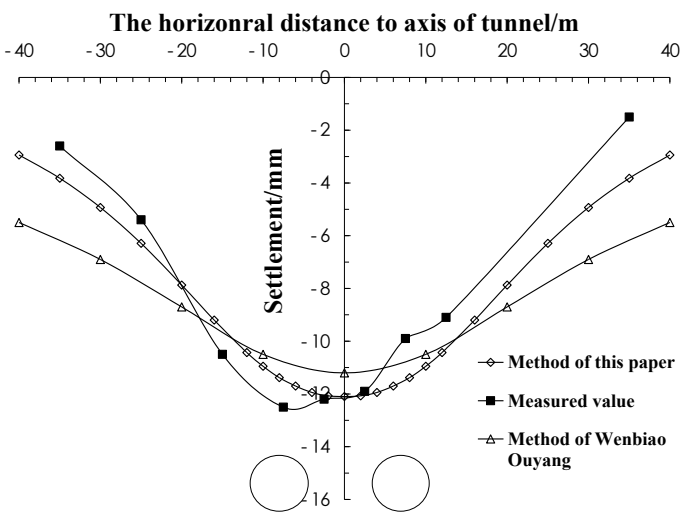

Fig.5. Comparison of calculated and measured curves of settlement

\subsection{Subway Line in Beijing}

In Beijing, there is a bi-directional bored tunnel that has been constructed using a mine tunneling method. The tunnel diameter is $7 \mathrm{~m}$ and the tunnel axis depth is about $20 \mathrm{~m}$. The axis spacing between the two tunnels is about $11 \mathrm{~m}$. Above the tunnel, there is a hotel building that is a brick and concrete structure, with four storeys. There is also a local building with three storeys. Both buildings are about $17 \mathrm{~m}$ high. The plane position relation between the building and the tunnel is shown in Fig. 6. The equivalent elastic modulus for the hotel building after conversion is $E_{1}=50 \mathrm{MPa}$. The ground is considered to be a homogenous linear elastic material. As per the empirical formula $E_{2}=2.5-3.5 E_{\mathrm{s}}$, for this project, $E_{\mathrm{s}}$ is chosen to be $10 \mathrm{MPa}$ and $E_{2}$ is chosen to be 30 $\mathrm{MPa}$. The transverse surface settlement, which is calculated using the modified stiffness method of HAN Xuan, and the measured settlement of the three measurement points $(001$, 008, 007) are shown in Fig. 6.

When the method proposed here is applied to the calculation, the $1.5 \mathrm{~m}$ buried depth of the building foundation is considered. After conversion, the hotel building is equivalent to a soil stratum $29.05 \mathrm{~m}$ thick, with the same properties as the soil stratum below it. The calculation parameters are chosen as follows: $g=88.05 \mathrm{~mm}$, i.e. $\eta=2.3 \%$, and $d=0.5 R$. See Fig. 6 for the lateral settlement curve of the foundation calculated by the method proposed here.
As shown in the figure, compared with the method of HAN Xuan, the settlement curve derived by the current method is more consistent with the measured settlement curve of the building, which shows the reliability of the proposed method.

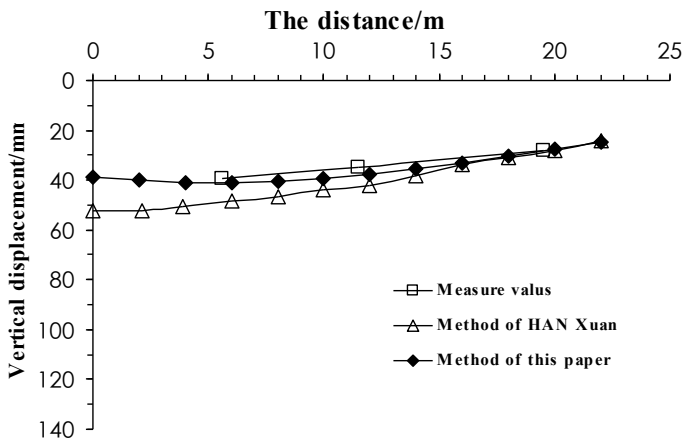

Fig.6. Predicted and measured settlement curves

\subsection{Comparison with Finite-Element Simulation Results}

Wei et al. [21] applied a three-dimensional finite-element method to simulate the foundation settlement of the building when a double-track tunnel passes directly under a building with a cross-beam base frame structure. The tunnel has an axis buried depth of $h=12 \mathrm{~m}$, a diameter of $D=6.3 \mathrm{~m}$ and a tunnel center spacing of $L=12 \mathrm{~m}$. The frame structure building has a height of $14.4 \mathrm{~m}$ and a length of $33 \mathrm{~m}$. The buried depth of the foundation is $2 \mathrm{~m}$. The equivalent elastic modulus of the building is $E_{1}=55 \mathrm{MPa}$. The uniform ground elastic modulus is $E_{2}=8 \mathrm{MPa}$.

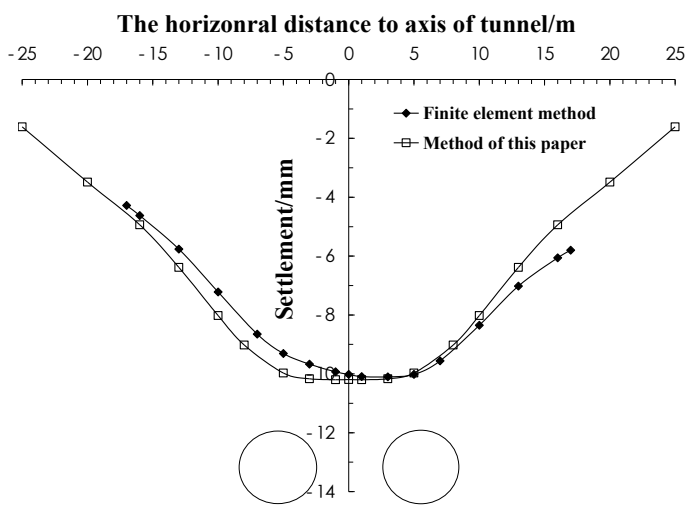

Fig.7. Comparison of the finite-element and uniform ground movement models for shield tunnels

When the current method is applied to the calculation, the buried depth of the building is considered. After conversion, the building is equivalent to a soil stratum 31.2 $\mathrm{m}$ thick, and has the same properties as the soil stratum below it. The calculation parameters are chosen as follows: $d=0.35 R$ and $g=21.14 \mathrm{~mm}$, i.e. $\eta=0.67 \%$ (see Fig. 7 ). For the lateral settlement curve of the foundation calculated using the current method, as shown in the figure, the results correspond well with the finite-element simulation values, which shows that the proposed method here is of better applicability. During the finite-element simulation of the double-track tunnel, it was assumed that the right-hand track was first excavated, which will result in asymmetry of the settlement curve. 
Chun-lai Chen, Hao-qiang Yu, Gang Wei, Xiao Wang, and Qi Ye

Journal of Engineering Science and Technology Review 8 (3) (2015) 179 - 184

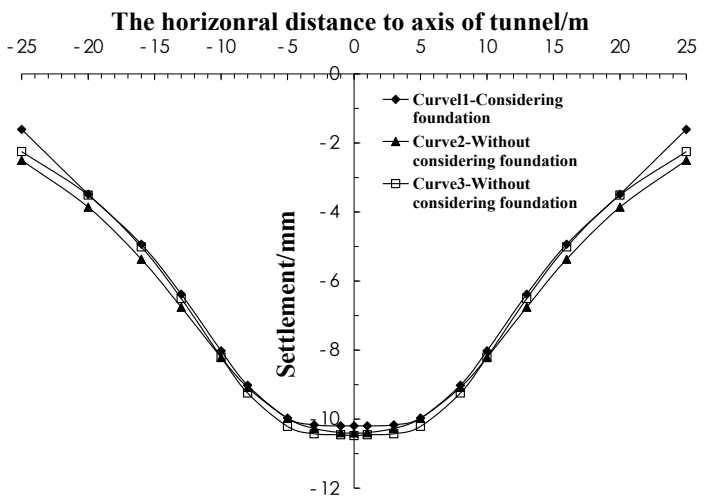

Fig.8. Comparison of settlement with consideration of the foundation and without consideration of the foundation

Next, the influence of the building foundation on the settlement was analyzed. Three sets of curves are calculated, as shown in Fig. 8. In the figure, curve 1 is the settlement curve at the original base plane with the foundation being considered, curve 2 is the settlement curve at the original ground surface with the foundation not being considered and curve 3 is the settlement curve at the original base plane with the foundation not being considered. As shown in the figure, the calculation results show that the building foundation has an impact on the settlement. The seat of the settlement for the case where the foundation is considered is bigger than for the case where the foundation is not considered, and the maximum settlement value at the center axis is relatively smaller.

\subsection{Analysis of Influential Factors}

Taking Chongsi Building of Xuhui Middle School in Shanghai as an example, the influential factors were investigated by changing the calculation parameters $E_{1}, h$ and $L$. The investigation only focused on single-factor analysis, with other calculation parameters being kept unchanged.

\subsubsection{Influence of the Equivalent Elastic Modulus of the Building on Foundation Settlement}

The values of the equivalent elastic modulus of building $E_{1}$ are changed to $50 \mathrm{MPa}, 80 \mathrm{MPa}$ and $110 \mathrm{MPa}$. The settlement curve can be calculated using formula (8) (see Fig. 9 for the results).

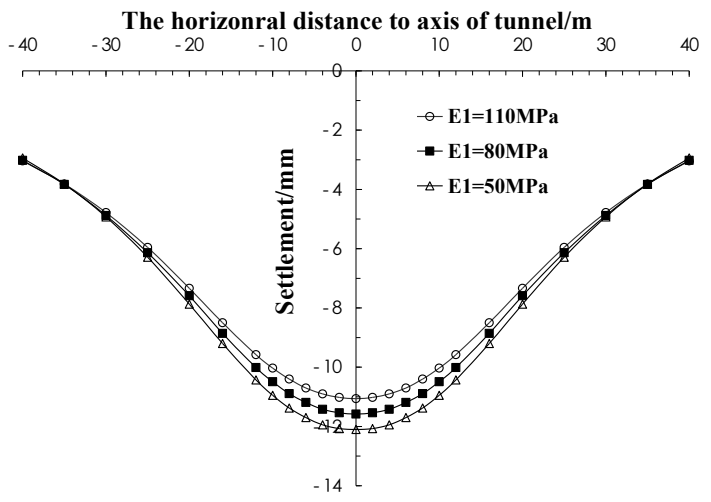

Fig.9. Influence of building stiffness on settlement

As shown in the figure, following an increase of the equivalent elastic modulus of the building, because the total amount of ground loss is the same, the influence scope of the settlement trough is nearly unchanged. The maximum settlement value at the bottom of the building foundation slightly decreases; when $E_{1}=50 \mathrm{MPa}, 80 \mathrm{MPa}$ and $110 \mathrm{MPa}$, the maximum settlement values at the bottom of the foundation are $12.1 \mathrm{~mm}, 11.58 \mathrm{~mm}$ and $11.06 \mathrm{~mm}$, respectively.

\subsubsection{Influence of Tunnel Axis Depth on Foundation Settlement}

The tunnel axis depth $h$ is changed to $2 D, 3 D$ and $4 D$. The settlement curve is calculated as per formula (8) (see Fig. 10 for the results). As shown in the figure, following the increase of the tunnel axis depth, the scope of the settlement trough increases, and the settlement curve shifts from a normal distribution to a $\mathrm{V}$ shape. The maximum settlement at the bottom of the building foundation decreases. When $h=2 D, 3 D$ and $4 D$, the maximum settlement values at the bottom of the foundation are $14.37 \mathrm{~m}, 13.16 \mathrm{~mm}$ and 11.98 $\mathrm{mm}$, respectively. Therefore, when the tunnel depth is too small, reinforcing control measures need to be taken to ensure that the settlement is within a reasonable range, so that the safety of the building can be guaranteed.

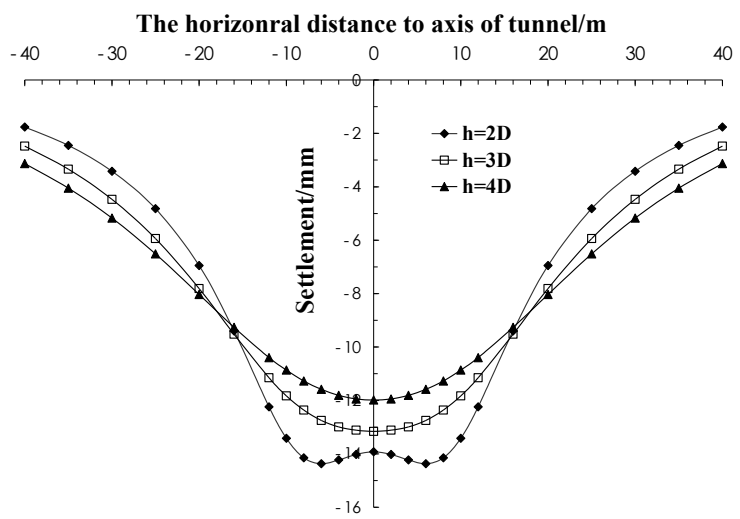

Fig.10. Influence of buried depth on settlement

\subsubsection{Influence of Axis Spacing of the Double-track Tunnel on Foundation Settlement}

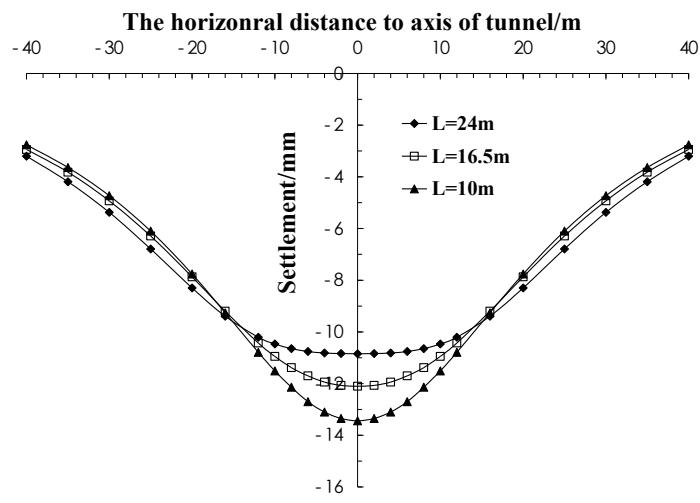

Fig.11. Influence of twin tunnel interval on settlement

The axis horizontal spacing of the double-track tunnel is changed to $10 \mathrm{~m}, 16.5 \mathrm{~m}$ and $24 \mathrm{~m}$. The settlement curve is calculated as per formula (8) (see Fig. 11 for the results). As shown in the figure, following an increase of the axis horizontal spacing of the double-track tunnel, the scope of the settlement trough becomes wider, while there is less change to the shape of the settlement curve. The maximum settlement value at the bottom of the building foundation obviously becomes small. When $L=10 \mathrm{~m}, 16.5 \mathrm{~m}$ and $24 \mathrm{~m}$, 
Chun-lai Chen, Hao-qiang Yu, Gang Wei, Xiao Wang, and Qi Ye

/Journal of Engineering Science and Technology Review 8 (3) (2015) 179 - 184

the maximum settlement values at the bottom of the foundation bottom are $13.44 \mathrm{~mm}, 12.10 \mathrm{~mm}$ and $10.85 \mathrm{~mm}$, respectively. Therefore, when the spacing of the doubletrack tunnel increases, the settlement superposition effect of the two tunnels decreases, which will result in a decrease of the maximum settlement value at the bottom of the building foundation.

\section{Conclusions}

A practical uniform ground movement model for shield tunnels was applied in the method proposed in this paper. At the same time, building foundation stiffness was considered, and instead of building settlement, the foundation base settlement was calculated. Case analysis demonstrated that, compared with the Wenbiao Ouyang method, the results calculated using the current method were more consistent with the measured values and the finite-element simulation results.

Following an increase of the equivalent elastic modulus of the building, the scope of the settlement trough was nearly unchanged, while the maximum settlement value at the foundation bottom slightly decreased. Following an increase of the tunnel axis depth, the scope of the settlement trough became wider and the settlement curve shifted from a normal distribution to a $\mathrm{V}$ shape. The maximum settlement value at the foundation bottom decreased. Following an increase of the axis horizontal spacing of the double-track tunnel, the scope of the settlement trough became wider, while there was less change to the shape of the settlement curve. The maximum settlement value at the bottom of the foundation obviously became small.

The building foundation had an impact on the settlement. The seat of the settlement for the case when the foundation was considered was bigger than the case when the foundation was not considered, while the maximum settlement value at the central axis became relatively smaller.

The method proposed in this paper applies to the case when the shield tunnel passes directly under a building and the building length covers the whole scope of the settlement trough. However, the current method still has some limitations. The same values as the parameters of two tunnels were chosen when the calculation was for doubletrack shield tunnels, which led to some differences between the calculated values and the measured values (especially when $L$ was small). Therefore, further study is required.

\section{Acknowledgements}

This work was financially supported by science and technology project plan of Mnistry of Housing and UrbanRural Development of the People's Republic of China in 2015 (NO:2015-K5-026).

\section{References}

1. Tomislav Hrestak, Antonia Jaguljnjak Lazarević, Lidija Frgić. "Stress and strain analysis during the sleme tunnel excavation", Tehnički vjesnik - Technical Gazette, 22(3), 2015, pp.703-709.

2. Tadeusz Majcherczyk, Zbigniew Niedbalski, Michał Kowalski. "3D numerical modeling of road tunnel stability-the Laliki project", Archives of Mining Sciences, 57(1), 2012, pp.61-78.

3. Gomez-Cabrera, Jose. "A pioneering system for risk control in the Sants-Sagrera high-speed tunnel in Barcelona SENER was the company responsible for the implementation of this system", Dyna, 88(2), 2013, pp.161-163.

4. Wang, J. X., Zou, B. P., Fu, H. X., et al. "Prediction of ground settlement induced by an extra-large diameter shield passing under sensitive buildings", Modern Tunnelling Technology, 50(5), 2013, pp. 98-104.

5. Liu, X. Y., Yuan, D. J., Qiao, G. G., et al. "Safe shield tunnelling under buildings", Modern Tunnelling Technology, 51(2), 2014, pp. 147-151.

6. Ouyang, W. B., Ding, W. Q., and Xie. D. W., "Calculation method for settlement due to shield tunnelling considering structure stiffness", Chinese Journal of Underground Space and Engineering, 9(1), 2013, pp. 155-160.

7. Chungsik, Y., and Jae-Hoon. K., "A web-based tunneling-induced building/utility damage assessment system: TURISK ", Tunnelling and Underground Space Technology, 18(5), 2003, pp. 497-511.

8. Han, X., Standing, J. R., and Li, N., "Modified stiffness approach to predict deformation of building induced by tunneling", Chinese Journal of Geotechnical Engineering, 31(4), 2009, pp. 39-545.

9. Mroueh, H., Shahrour, I., "A full 3-D finite element analysis of tunnelling-adjacent structures interaction", Computers and Geotechnics, 30(3), 2003, pp.245-253.

10. Peng, C., Ji, Y. L., Luo, H. B., et al. "Numerical simulation of effects of double-tube parallel shield tunneling on neighboring building ", Chinese Journal of Rock Mechanics and Engineering, 27(Supp.2), 2008, pp. 3868-3874.
11. Liao, S. M., Liu, J. H., Wang, R. L., Li, Z. M., "Shield tunnelling and environment protection in Shanghai soft ground", Tunnelling and Underground Space Technology, 24(4), 2009, pp.454-465.

12. Pickhaver, J. A., Burd, H. J., Houlsby, G. T., "An equivalent beam method to model masonry buildings in 3D finite element analysis", Computers and Structures, 88(19-20), 2010, pp.1049-1063.

13. Xu, Z. M., Han, Q. H., Zheng, G., et al. "Field monitoring and analysis of effects of metro tunnels under historic buildings", Chinese Journal of Geotechnical Engineering, 35(2), 2013, pp. 364-374.

14. Shen, J. Y., "Impact of shield driving on the security of buildings along Chengdu metro line 1", Modern Tunnelling Technology, 45(2), 2008, pp. 63-68.

15. Sun, Y. K., and Guan, F. L., "Shield tunnel construction induced influence on the settlement of masonry buildings", China Railway Science, 33(4), 2012, pp. 38-44.

16. Verruijt, A., and Booker, J. R., "Surface settlements due to deformation of a tunnel in an elastic half plane", Geotechnique, 46(4), 1996, pp. 753-756.

17. Wei, G., "Prediction of ground deformation induced by shield tunneling construction", Chinese Journal of Rock Mechanics and Engineering, 28(2), 2009, pp. 418-424.

18. Wei, G., "Establishment of uniform ground movement model for shield tunnels", Chinese Journal of Geotechnical Engineering, 29(4), 2007, pp. 554-559.

19. Wei, G., and Liu, J.W., "Study on parameter selection of uniform ground movement pattern of shield tunnel", Railway Engineering, (2), 2009, pp. 48-51.

20. Yang, M., and Zhao, X. H., "An approach for a single pile in layered soil", Journal of Tongii University, 20(4), 1992, pp. 421428.

21. Wei, G., Guo, Q. G., and Hong, J., "Effect analysis of double-line parallel shield tunnel crossing frame structure building based on GTS", Applied Mechanics and Materials, (99-100), 2011, pp. 10821086. 